\title{
Radiation protection value to the operator from augmented reality smart glasses in interventional fluoroscopy procedures using phantoms
}

\author{
Shaun Dorey ${ }^{{ }^{*}}$, Lucinda Gray ${ }^{1}$, Andrew Tootell ${ }^{1}$, Robert Higgins ${ }^{1}$, Shofiq Al- \\ Islam $^{2}$, Helen Baxter ${ }^{3}$, Paul Dixon ${ }^{4}$ and Peter Hogg ${ }^{1}$ \\ ${ }^{1}$ Directorate of Radiography, University of Salford, UK \\ 2 Department of Radiology, Royal Blackburn Hospital, UK \\ ${ }^{3}$ Department of Radiology, Tameside General Hospital, UK \\ ${ }^{4}$ Rothband, Burnley, UK \\ *Corresponding author. University of Salford, Directorate of Radiography, Floor 6, \\ Allerton Building, University of Salford, Lancashire, Salford, United Kingdom, M5 \\ 4WT
}

\section{Email address: s.dorey2@edu.salford.ac.uk}

Declarations of interest: none

\begin{abstract}
Introduction: Smart glasses can be adapted to display radiographic images to allow clinician's gaze not to be directionally fixed or predetermined by computer monitor location. This study presents an analysis of eye lens dose during interventional fluoroscopy guided procedures, comparing fixed monitor positions against the use of smart glasses.

Methods: Using a head phantom (simulating the clinician), thermoluminescent dosimeters and lead shielded glasses, the dose to the eye was measured for different head 'rotations and tilts' for: gaze directed towards the main scattering source (patient / primary beam) to represent potential gaze direction if smart glasses are used; gaze directed to a range of potential computer monitor positions. An anthropomorphic pelvis phantom was utilised to simulate the patient. Accumulated dose rates $\left(\mu \mathrm{Gy}_{\mathrm{s}} \mathrm{s}^{-1}\right)$ from five 10-second exposures at $75 \mathrm{kV} 25.2 \mathrm{mAs}$ were recorded.

Results: An average DAP reading of $758.84 \mathrm{cGy} . \mathrm{cm}^{2}$ was measured during each 10 second exposure. Whilst wearing lead shielded glasses a 6.10 - fold reduction in dose rate to the lens is possible $(\mathrm{p}<0.05)$. Influence of the direction of gaze by the clinician demonstrated a wide range of dose rate reduction from $3.13 \%(p=0.16)$ to $143.69 \%(p<0.05)$ when the clinician's gaze was towards the main scattering source. Increased dose rate to the clinician's eyes was received despite wearing lead shielded glasses, as the angle of gaze moved $45^{\circ}$ and $90^{\circ}$ from $0^{\circ}$.

Conclusion: If the clinician's gaze is directed towards the main scattering source a potential exists for reducing eye lens dose compared with fixed location computer monitors. Introduction of lead lined smart glasses into interventional radiology may lead to improvements in patient care, reducing the need for the clinician to look away from the patient to observe a radiographic image.
\end{abstract}




\section{Introduction}

The introduction of smart glasses, such as Google Glass, ${ }^{1}$ has enabled real time communication via the internet to facilitate information exchange through integrated display screens, high definition camera, microphone; wireless connectivity allows the wearer to be independent of physical internet connections. This technology has the potential to be used by medical and surgical practitioners in both practise ${ }^{2,3}$ and education. ${ }^{4}$

The potential for smart glasses in interventional radiology has previously been considered, ${ }^{5-7}$ concluding that they can offer improvements in patient safety, operator comfort and procedure efficiency. During these procedures the clinician may be looking at their hands, equipment or a real time image on a computer monitor produced either by a Computer Tomography (CT) scanner, fluoroscopy or an ultrasound machine. ${ }^{7}$ The location of these monitors however may not be convenient, requiring the clinician to look away from their hands and patient. It may also be required to move the monitors during procedures when manipulating the $\mathrm{C}$ arm into cranial and caudal angles. Furthermore, the monitors may be partially obscured by other equipment. The use of smart glasses may offer a solution to these problems, enabling the clinician to direct their gaze wherever they like as the images would appear within the smart glasses rather than on computer monitors located somewhere in the clinical room. ${ }^{8}$ In turn this may result in procedures being completed faster and safer as the clinician would be able to observe the live radiographic image without looking away from the patient. Additionally, clinicians are able to record the procedure for future teaching purposes. ${ }^{7}$

Aside from improving safety and efficiency, smart glasses have potential radiation protection benefits to clinicians. Damage to biological tissue by ionising radiation is dependant partly on the amount of radiation received ${ }^{9}$ and its use in medicine is continuously increasing. ${ }^{10}$ Fluoroscopy is often the imaging technique of choice for interventional radiology procedures, but it is associated with a higher radiation dose, ${ }^{11,} 12$ especially in relation to the clinician's eye lens. The lens of the clinician's eye is one of the most radiosensitive structures in the human body and is located within a high intensity region for fluoroscopy radiation dose. ${ }^{13,14}$ The potential of radiation to cause lens opacities or cataracts is deterministic and has been highlighted in the 2011 International Commission on Radiological Protection (ICRP) publication 118. This makes it essential for eye lens protection to be worn by clinicians during fluoroscopy guided procedures, especially for any clinician who has to stand close to the patient and the $x$-ray source. ${ }^{15-17}$ Dose limits set by the ICRP for the eye lens are $20 \mathrm{mSv}$ per year over 5 years for the lens, with a maximum of 50 mSv per year. ${ }^{18}$

Previous work has focussed either on the reduction of eye dose whilst wearing lead shielded glasse ${ }^{17}$ or how smart glasses (not lead lined) may influence the clinician's practise during interventional fluoroscopy procedures. ${ }^{8}$ To the authors' knowledge no research has been conducted on what the dose implications would be to the 
clinician's eyes if wearing lead lined augmented reality smart glasses. Using phantoms, this study's purpose was to analyse radiation dose to a simulated clinician's eyes during interventional fluoroscopy-guided procedures comparing fixed monitor positions against the use of smart glasses.

\section{Methods}

A quality controlled Ultimax-i Toshiba Fluoroscopy (Canon Medical Systems, Japan) machine was used; the recommended standards for routine performance test results complied with IPEM report No $91^{19}$ and the machine was in routine clinical use. An adult lower sectional torso RSD anthropomorphic pelvis phantom RS-113T (Universal Medical, USA) was utilised to simulate an average male patient, representing comparable absorption and scattering characteristics of human tissue. The phantom was positioned supine on the imaging table and centred at the midline of the couch, simulating an actual clinical setting. The table was raised to a height of 1 meter from the floor and the fluoroscopy flat panel detector was $32 \mathrm{~cm}$ above the table top. This set up was based on a similar phantom experiment measuring clinician eye doses in interventional fluoroscopy procedures. ${ }^{17}$ The centring point used during the examination was in the midline between the anterior superior iliac spine and superior border of the pubic symphysis, which is a typical centring point for an anteroposterior (AP) pelvis. Collimation was kept at maximum throughout the experiment at $43 \times 43 \mathrm{~cm}$ to allow sufficient scatter for the collection of reliable data for this study. There was no angulation of the $C$ arm to maintain experimental set-up.

A Rando anthropomorphic head phantom SK150 (The Phantom Laboratory, USA) simulating the clinician was positioned to the right of the patient representing a clinical environment, at a distance of $60 \mathrm{~cm}$ perpendicular from the nearest edge of the flat panel detector. It is known that at this position the clinician will be exposed to the least amount of radiation, due to a shielding effect caused by the flat panel detector. ${ }^{20}$ The height of the head phantom was $168.5 \mathrm{~cm}$, determined by the mean average height of both a male and female British person. ${ }^{21}$

Accumulated dose rates to the clinician's eye lenses from five 10-second exposures at $75 \mathrm{kV} 25.2 \mathrm{mAs}$ with a focal spot size of $1 \mathrm{~mm}$ and a tantalum filter were recorded for different angles of gaze to decrease random error, therefore promoting higher levels of accuracy. The acquisition parameters were consistent with those used in a clinical fluoroscopy guided percutaneous procedure for the pelvis. ${ }^{22}$ Flat panel detector exposures were made with the phantom head, with no cranial or caudal angulation, at $0^{\circ}, 45^{\circ}$, and $90^{\circ}$ horizontal gazes to represent clinician gaze towards fixed location computer monitors. Each direction of gaze has been labelled $A-E$ as shown in Figure 1 for reference. Directions $B-D$ were repeated with the phantom head tilted at a caudal angle of $15^{\circ}$ to represent potential gaze of the clinician if smart glasses are worn (towards the main scattering source / patient). Rothband Sportswrap lead shielded glasses with $0.75 \mathrm{~mm} \mathrm{~Pb}$ lens and 0.50 $\mathrm{mm} \mathrm{Pb}$ side shields (Rothband, England, UK) ${ }^{23}$ were used to cover the eyes of the 
phantom. The experiment was conducted for each angle of gaze both with and without the head phantom wearing the lead shielded glasses. Figure 2 shows the setup of the experiment.

Nine calibrated high sensitivity LiF:Mg, Cu thermoluminescent dosimeters (TLDs) type $\mathrm{P}-100 \mathrm{H}$ (Thermo Scientific, USA) were used to measure the cumulated radiation dose on both the left and right eye of the phantom, arranged as shown in Figure 3. Their tissue equivalency $\left(Z_{\text {eff }} T L D=8.04\right.$ compared to $Z_{\text {eff tissue }}=7.42$ ) has a similar response to radiation as human tissue. ${ }^{24}$ The dose rate $\left(\mu \mathrm{Gy} . \mathrm{s}^{-1}\right)$ for each eye was calculated from the accumulated dose of all 9 TLDs by determining their mean value. The mean value was then divided by 5 to give the mean value of the five 10second exposures. The mean value was then further divided by 10 to give the dose rate in seconds. The TLDs used on the day of the experiment were from 3 different batches and were calibrated separately per batch as described by Tootell, Szczepura, and Hogg (2013). ${ }^{25}$ An uncertainty of less than $10 \%$ total in dosimetric results by TLDs has to be achieved in accordance with the European Commission. ${ }^{26}$ Sensitivity difference of each batch was determined to be less than $3 \%$. Calculated consistency was $99 \%$ and total uncertainty was $4 \%$. To remove any residual charge the TLDs were annealed at $240^{\circ} \mathrm{C}$ for 10 minutes in a rapid cooling oven (TLD/3, Carbolite, England, UK) equipped with a Eurotherm 3508 temperature programmable controller. The TLDs were read in a Harshaw 3500 TLD (Thermo Scientific, USA), with associated software (WinREMS) on a personal computer. ${ }^{24}$ The experiment was conducted in a single time slot over one day.

Bar charts were produced to compare dose rates at different directions of gaze both with and without lead shielded glasses. A percentage difference comparison between dose rate received at fixed monitor positions against the clinician's gaze directed towards the main scattering source (representing the use of smart glasses) for each eye was calculated from

$$
\frac{\left|V_{1}-V_{2}\right|}{\frac{\left(V_{1}+V_{2}\right)}{2}} \times 100
$$

Where $V_{1}$ and $V_{2}$ are value 1 and value 2 of dose rate, respectively. A Shapiro - Wilk (SW) test was applied to assess the normality of the data to select a suitable statistical test for data analysing. A paired t-test (for parametric data) was utilised to compare the dose rate measured by the 9 TLDs with and without wearing lead shielded glasses across different angles of gaze at a horizontal angle and at a $15^{\circ}$ caudal angle for both the left and right eye. 


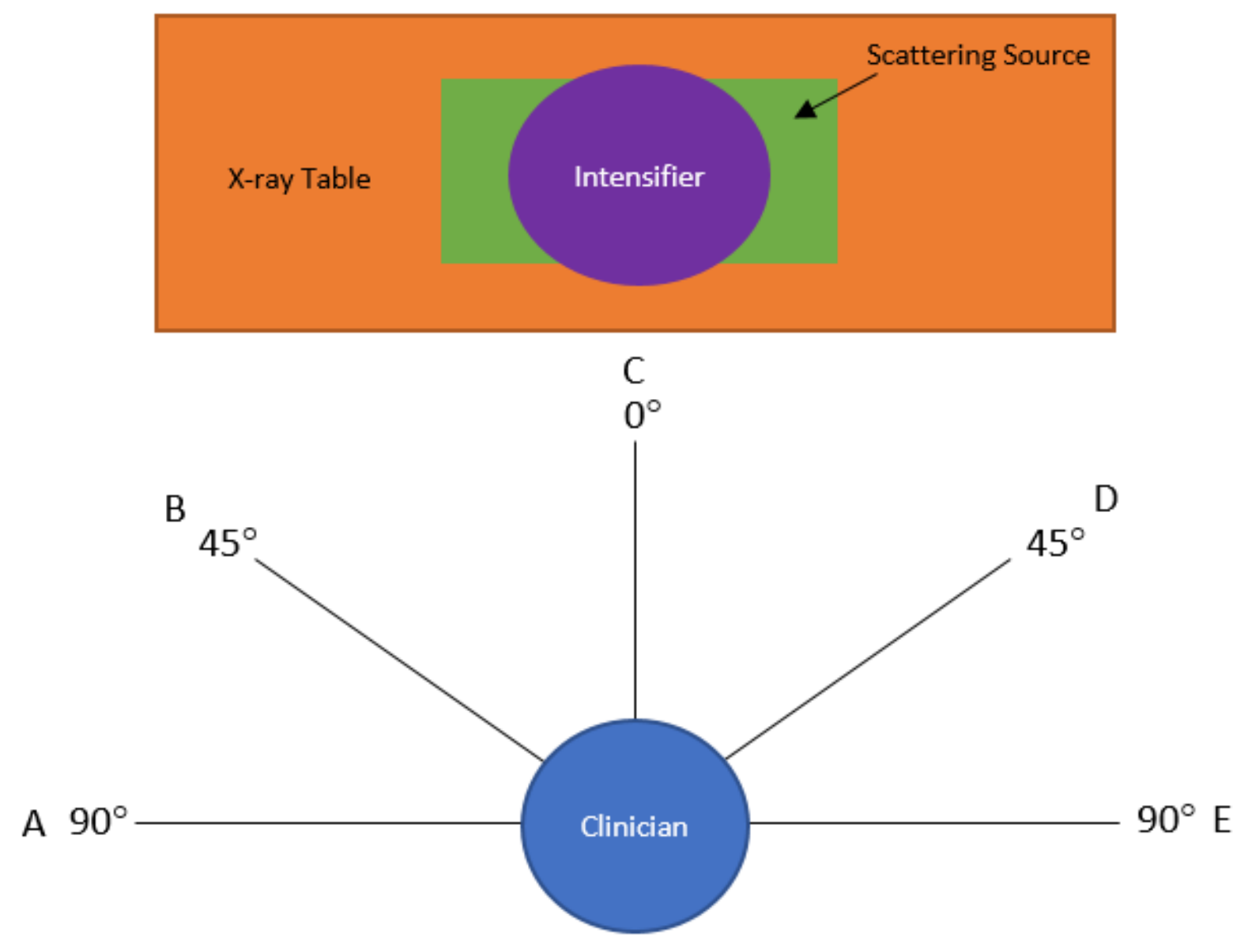

Figure 1. Diagram representing clinician's angle of gaze ( $A$ - E used for reference). 


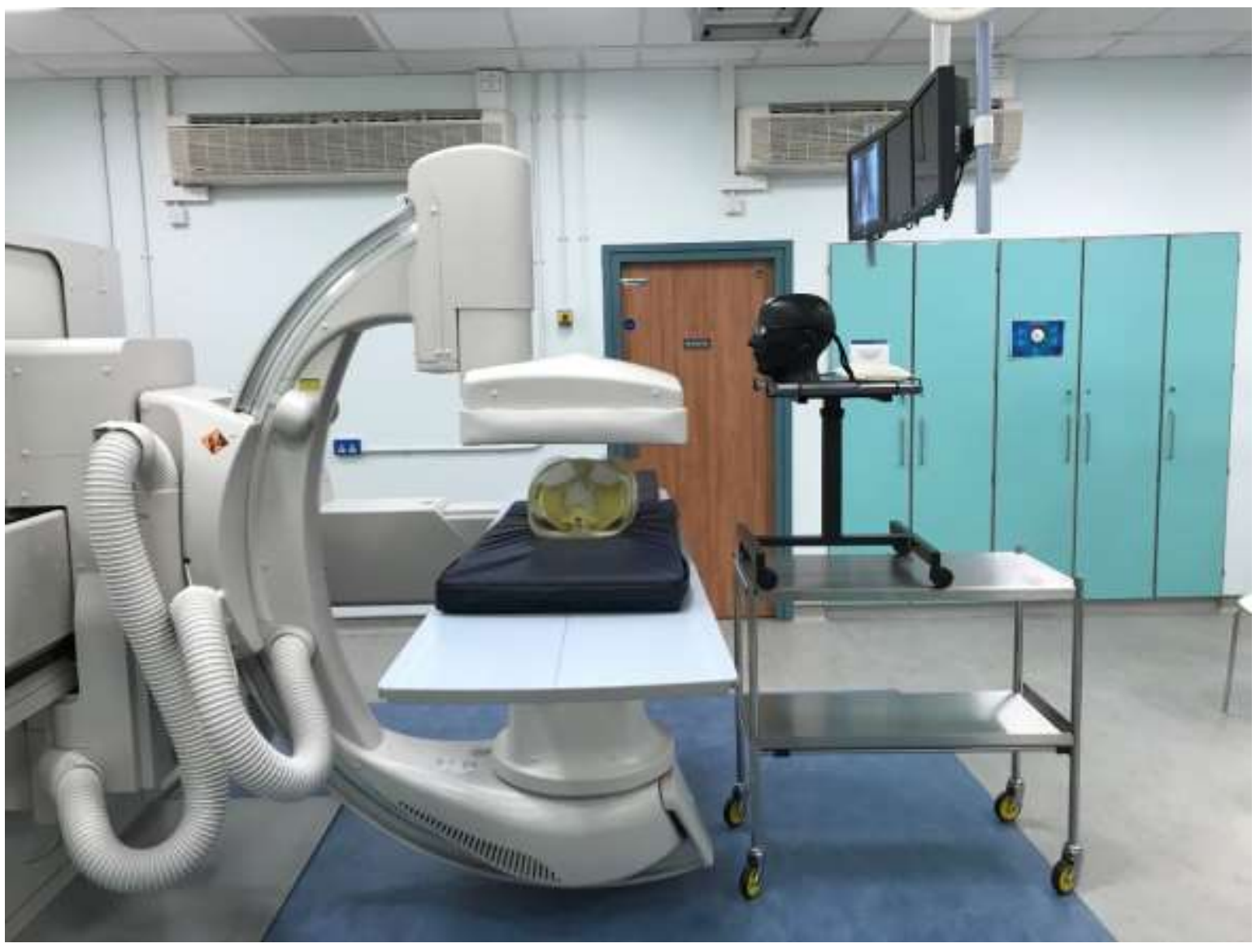

Figure 2. Experimental set up. 


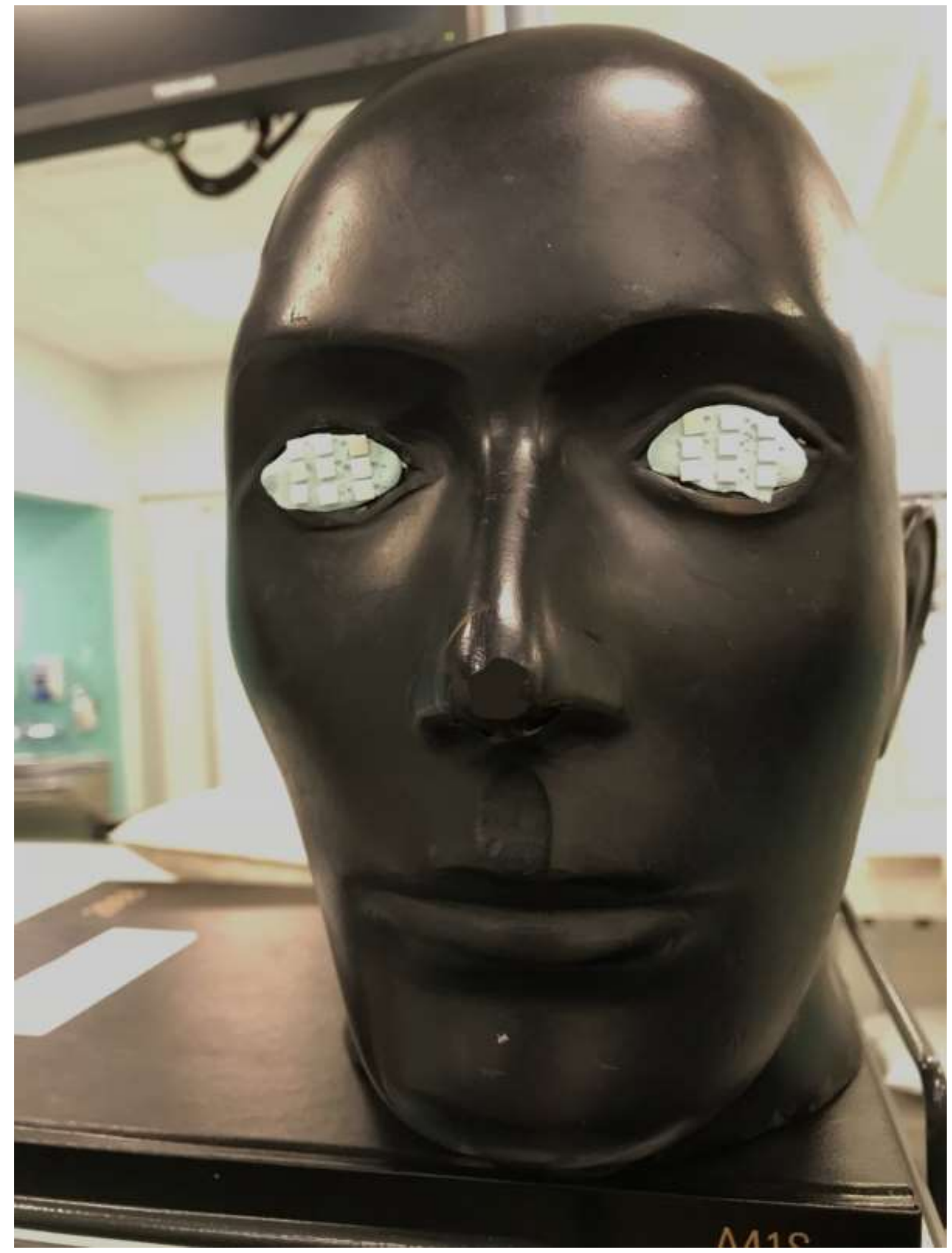

Figure 3. TLD arrangement on simulated clinician's eyes. 


\section{Results}

A comparison between the dose rate received from the simulated clinician's eyes for the varying head positions $\mathrm{A}-\mathrm{E}$ with no $15^{\circ}$ caudal angle (as represented in Figure 1) with and without wearing lead shielded glasses is presented in Figure 4. The SW test showed a normal distribution for all the data, hence error bars were calculated by standard deviation from the dose rate of the 9 TLDs on each eye. A reduction in dose rate for both eyes was greatest when the simulated clinician's gaze was in position $\mathrm{C}$, looking directly at the main scattering source whilst wearing lead shielded glasses. This is also seen when the experiment was repeated with the simulated clinician's head at a $15^{\circ}$ caudal angle looking directly at the phantom pelvis (Figure 5.). The dose rate with the simulated clinician's head at a $15^{\circ}$ caudal angle is also smaller when compared with no head tilt. When the simulated clinician's gaze was at positions $A$ and $E$ with no $15^{\circ}$ caudal angle, the smallest reduction in dose rate was measured when the simulated clinician wore lead shielded glasses.

Tables 1 and 2 presents the scatter dose values for 10 second exposure ( $\mu \mathrm{Gy}$ ), dose rates values $\left(\mu \mathrm{Gy} \cdot \mathrm{s}^{-1}\right)$, and the differences in dose rate values as percentages for the varying simulated computer monitor positions versus the lowest dose rate measurement. The lowest dose rate measurement was identified as the simulated clinician's gaze at position $C$ with a $15^{\circ}$ caudal head tilt whilst wearing lead shielded glasses. The percentage difference was calculated to show what reduction in dose rate can be achieved if the clinician opted to use lead lined augmented reality smart glasses. Tables 3 and 4 show the $p$ values for the SW test and the $p$ values of the paired t-test of the 9 TLDs on each eye for the different angles of gaze. A paired $t-$ test calculation demonstrates that there is a statistically significant difference $(p<0.05)$ in dose rates with and without wearing lead shielded glasses for most angles. 


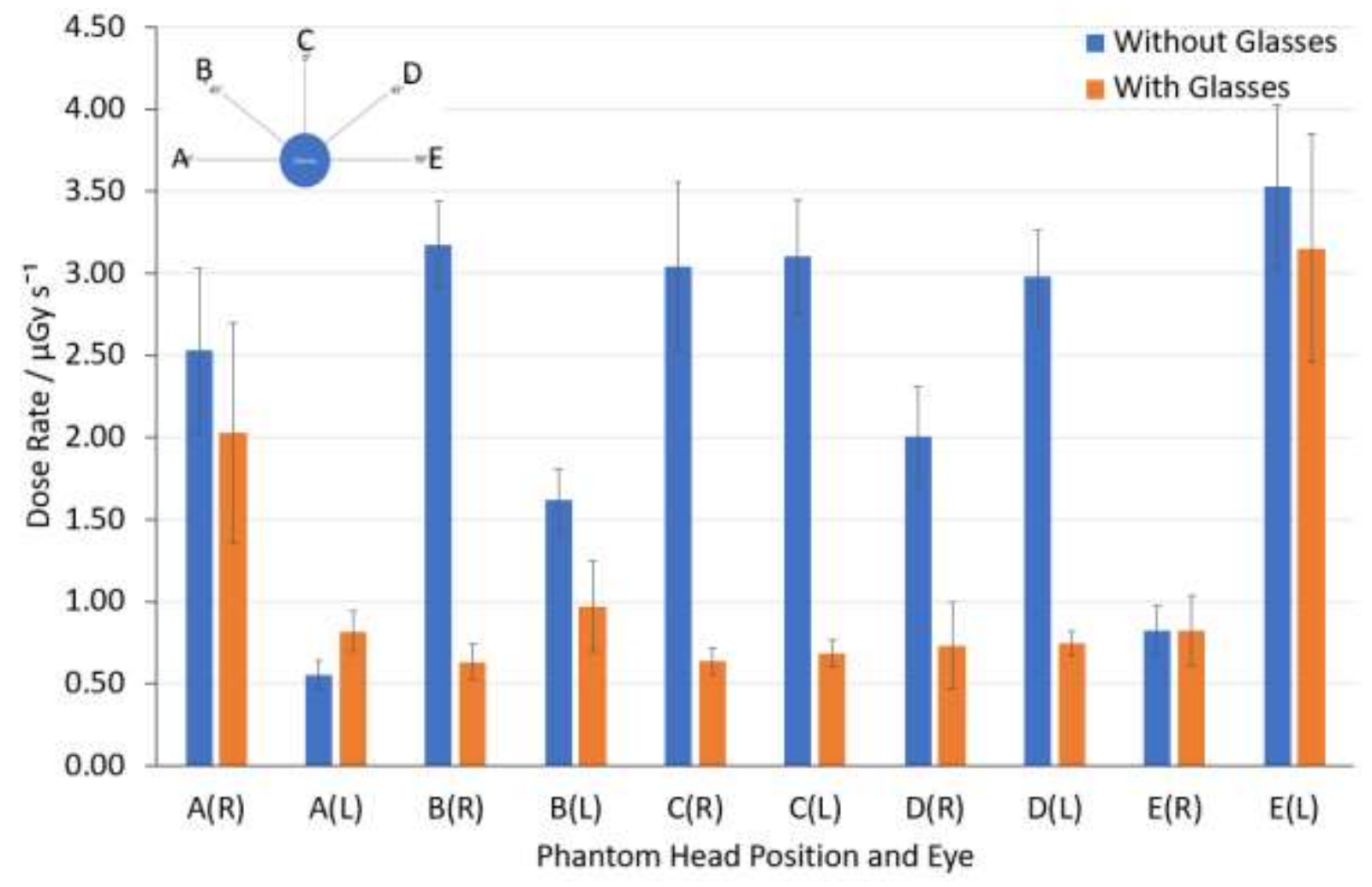

Figure 4. Comparison between the dose rate received to the simulated clinician's eyes at a horizontal angle for the varying head positions $A-E$, where $(R)$ and $(L)$ represent the right and left eye respectively and error bars represent standard deviation of the dose rate measured from 9 TLDs. 


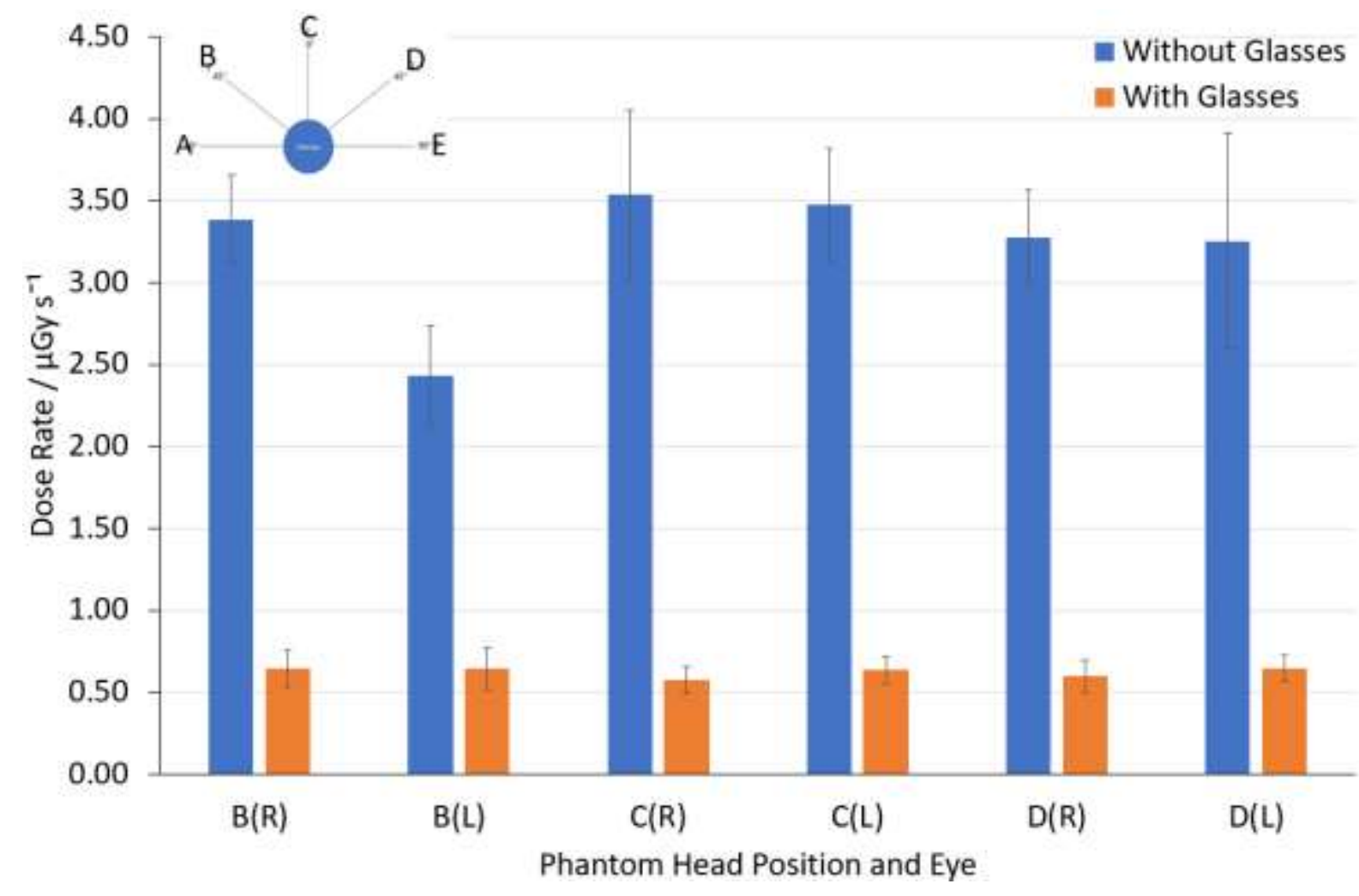

Figure 5. Comparison between the dose rate received to the simulated clinician's eyes at a $15^{\circ}$ caudal angle for the varying head positions $B-D$, where $(R)$ and $(L)$ represent the right and left eye respectively and error bars represent standard deviation of the dose rate measured from 9 TLDs. 
Table 1. Dose rates and the percentage dose rate difference in comparison to the lowest dose rate measured at the right eye $\left(0.58 \mu \mathrm{Gy} . \mathrm{s}^{-1}\right)$ and the left eye $(0.63$ $\left.\mu \mathrm{Gy} . \mathrm{s}^{-1}\right)$ for the different angles of gaze at a horizontal angle.

\begin{tabular}{|c|c|c|c|c|c|}
\hline Angle of Gaze & $\begin{array}{c}\text { Eye } \\
\text { Right (R) / } \\
\text { Left (L) }\end{array}$ & $\begin{array}{c}\text { Lead } \\
\text { Shielded } \\
\text { Glasses } \\
(\mathrm{Y} / \mathrm{N})\end{array}$ & $\begin{array}{c}\text { Scatter Dose } \\
\text { for } 10 \\
\text { second } \\
\text { exposure } \\
(\mu \mathrm{Gy})\end{array}$ & $\begin{array}{c}\text { Dose Rate } \\
\left(\mu \mathrm{Gy} \cdot \mathrm{s}^{-1}\right)\end{array}$ & $\begin{array}{l}\text { Percentage } \\
\text { difference of } \\
\text { dose rate }\end{array}$ \\
\hline$A$ & $\mathrm{R}$ & $\mathrm{Y}$ & 20.31 & 2.03 & 111.11 \\
\hline$A$ & $R$ & $\mathrm{~N}$ & 25.28 & 2.53 & 125.40 \\
\hline A & L & $\mathrm{Y}$ & 8.19 & 0.82 & 26.21 \\
\hline A & $\mathrm{L}$ & $\mathrm{N}$ & 5.56 & 0.56 & 11.76 \\
\hline$B$ & $R$ & $\mathrm{Y}$ & 6.32 & 0.63 & 8.26 \\
\hline$B$ & $\mathrm{R}$ & $\mathrm{N}$ & 31.76 & 3.18 & 138.30 \\
\hline$B$ & $\mathrm{~L}$ & $\mathrm{Y}$ & 9.67 & 0.97 & 42.50 \\
\hline $\mathrm{B}$ & $\mathrm{L}$ & $\mathrm{N}$ & 16.19 & 1.62 & 88.00 \\
\hline$C$ & $R$ & $\mathrm{Y}$ & 6.39 & 0.64 & 9.84 \\
\hline C & $\mathrm{R}$ & $\mathrm{N}$ & 30.44 & 3.04 & 135.92 \\
\hline C & L & $\mathrm{Y}$ & 6.86 & 0.69 & 9.09 \\
\hline C & $\mathrm{L}$ & $\mathrm{N}$ & 31.05 & 3.11 & 132.62 \\
\hline $\mathrm{D}$ & $R$ & $\mathrm{Y}$ & 7.33 & 0.73 & 22.90 \\
\hline $\mathrm{D}$ & $\mathrm{R}$ & $\mathrm{N}$ & 20.02 & 2.00 & 110.08 \\
\hline $\mathrm{D}$ & $\mathrm{L}$ & $\mathrm{Y}$ & 7.45 & 0.75 & 17.39 \\
\hline $\mathrm{D}$ & $\mathrm{L}$ & $\mathrm{N}$ & 29.78 & 2.98 & 130.19 \\
\hline$E$ & $\mathrm{R}$ & $\mathrm{Y}$ & 8.22 & 0.82 & 34.29 \\
\hline $\mathrm{E}$ & $\mathrm{R}$ & $\mathrm{N}$ & 8.22 & 0.82 & 34.29 \\
\hline$E$ & $\mathrm{~L}$ & $\mathrm{Y}$ & 31.53 & 3.15 & 133.33 \\
\hline $\mathrm{E}$ & $\mathrm{L}$ & $\mathrm{N}$ & 35.31 & 3.53 & 139.42 \\
\hline
\end{tabular}


Table 2. Dose rates and the percentage dose rate difference in comparison to the lowest dose rate measured at the right eye $\left(0.58 \mu \mathrm{Gy} \cdot \mathrm{s}^{-1}\right)$ and the left eye $(0.63$ $\left.\mu G y . s^{-1}\right)$ for the different angles of gaze at a $15^{\circ}$ caudal angle.

\begin{tabular}{|c|c|c|c|c|c|}
\hline Angle of Gaze & $\begin{array}{c}\text { Eye } \\
\text { Right (R) / } \\
\text { Left (L) }\end{array}$ & $\begin{array}{c}\text { Lead } \\
\text { Shielded } \\
\text { Glasses } \\
(\mathrm{Y} / \mathrm{N})\end{array}$ & $\begin{array}{c}\text { Scatter Dose } \\
\text { for 10 } \\
\text { second } \\
\text { exposure } \\
(\mu \mathrm{Gy})\end{array}$ & $\begin{array}{c}\text { Dose Rate } \\
\left(\mu \mathrm{G} . \mathrm{s}^{-1}\right)\end{array}$ & $\begin{array}{c}\text { Percentage } \\
\text { difference of } \\
\text { dose rate }\end{array}$ \\
\hline B & $\mathrm{R}$ & $\mathrm{Y}$ & 6.43 & 0.64 & 9.84 \\
\hline B & $\mathrm{R}$ & $\mathrm{N}$ & 33.86 & 3.39 & 141.56 \\
\hline B & $\mathrm{L}$ & $\mathrm{Y}$ & 6.46 & 0.65 & 3.13 \\
\hline B & $\mathrm{L}$ & $\mathrm{N}$ & 24.35 & 2.44 & 117.92 \\
\hline C & $\mathrm{R}$ & $\mathrm{Y}$ & 5.75 & 0.58 & $\mathrm{~N} / \mathrm{A}$ \\
\hline C & $\mathrm{R}$ & $\mathrm{N}$ & 35.37 & 3.54 & 143.69 \\
\hline C & $\mathrm{L}$ & $\mathrm{Y}$ & 6.35 & 0.63 & $\mathrm{~N} / \mathrm{A}$ \\
\hline C & $\mathrm{L}$ & $\mathrm{N}$ & 34.75 & 3.47 & 138.54 \\
\hline $\mathrm{D}$ & $\mathrm{R}$ & $\mathrm{Y}$ & 6.01 & 0.60 & 3.39 \\
\hline $\mathrm{D}$ & $\mathrm{R}$ & $\mathrm{N}$ & 3.27 & 3.27 & 139.74 \\
\hline $\mathrm{D}$ & $\mathrm{L}$ & $\mathrm{Y}$ & 6.46 & 0.65 & 3.13 \\
\hline $\mathrm{D}$ & $\mathrm{L}$ & $\mathrm{N}$ & 32.50 & 3.25 & 135.05 \\
\hline
\end{tabular}


Table 3. Shapiro - Wilk (SW) test $p$ values and $p$ values of the paired t-test for the different angles of gaze at a horizontal angle.

\begin{tabular}{|c|c|c|c|c|}
\hline Angle of Gaze & $\begin{array}{c}\text { Eye } \\
\text { Right (R) / } \\
\text { Left (L) }\end{array}$ & $\begin{array}{c}\text { Lead Shielded } \\
\text { Glasses (Y/N) }\end{array}$ & SW p-value & $\begin{array}{c}\text { Paired t-test } \\
p \text {-value }\end{array}$ \\
\hline A & R & Y & 0.420 & $<0.05$ \\
\hline A & R & N & 0.647 & $<0.05$ \\
\hline A & L & Y & 0.234 & $<0.05$ \\
\hline A & L & N & 0.261 & $<0.05$ \\
\hline B & R & Y & 0.293 & $<0.05$ \\
\hline B & R & N & 0.764 & $<0.05$ \\
\hline B & L & Y & 0.570 & $<0.05$ \\
\hline B & L & N & 0.764 & $<0.05$ \\
\hline C & R & Y & 0.125 & $<0.05$ \\
\hline C & R & N & 0.445 & $<0.05$ \\
\hline C & L & Y & 0.668 & 0.19 \\
\hline C & L & N & 0.568 & $<0.05$ \\
\hline D & R & Y & 0.279 & 0.11 \\
\hline D & R & N & 0.295 & $<0.05$ \\
\hline D & L & Y & 0.778 & $<0.05$ \\
\hline D & L & N & 0.293 & $<0.05$ \\
\hline E & R & Y & 0.607 & $<0.05$ \\
\hline E & R & N & 0.527 & $<0.05$ \\
\hline E & L & Y & 0.697 & $<0.05$ \\
\hline E & L & N & 0.282 & $<0.05$ \\
\hline
\end{tabular}

Table 4. Shapiro - Wilk (SW) test $p$ values and $p$ values of the paired t-test for the different angles of gaze at a $15^{\circ}$ caudal angle

\begin{tabular}{|c|c|c|c|c|}
\hline Angle of Gaze & $\begin{array}{c}\text { Eye } \\
\text { Right (R) / } \\
\text { Left (L) }\end{array}$ & $\begin{array}{c}\text { Lead Shielded } \\
\text { Glasses (Y/N) }\end{array}$ & SW p-value & $\begin{array}{c}\text { Paired t-test } \\
p \text {-value }\end{array}$ \\
\hline B & R & Y & 0.504 & $<0.05$ \\
\hline B & R & N & 0.945 & $<0.05$ \\
\hline B & L & Y & 0.751 & 0.16 \\
\hline B & L & N & 0.590 & $<0.05$ \\
\hline C & R & Y & 0.646 & $\mathrm{~N} / \mathrm{A}$ \\
\hline C & R & N & 0.102 & $<0.05$ \\
\hline C & L & Y & 0.709 & $\mathrm{~N} / \mathrm{A}$ \\
\hline C & L & N & 0.675 & $<0.05$ \\
\hline D & R & Y & 0.318 & 0.43 \\
\hline D & R & N & 0.754 & $<0.05$ \\
\hline D & L & Y & 0.918 & 0.74 \\
\hline D & L & N & 0.408 & $<0.05$ \\
\hline
\end{tabular}




\section{Discussion}

This phantom - based study has shown the potential of wearing lead impregnated augmented reality smart glasses for reducing the amount of radiation received to the interventional clinician's eye lens. It has demonstrated that the clinician receives a higher rate of radiation dose during an exposure if looking away from the pelvis phantom and looking towards potential locations of monitors. As shown in tables 1 4 a percentage difference of dose rate can be attained from a range of $3.13 \%$ to $143.69 \%$. A paired t-test established that for most angles of gaze a statistical significant difference $(p<0.05)$ was observed. A few exceptions were determined where there is no statistically significant difference $(p>0.05)$ at angles B $-D$ when the clinician was wearing lead shielded glasses, where the dose measured was very similar with position $\mathrm{C}$ at a $15^{\circ}$ caudal angle. In realistic conditions the clinician will always turn towards the monitor when an exposure takes place..$^{20}$ The lowest dose rate recorded was when the angle of gaze was directly looking at the pelvis phantom. This is where, during an exposure, the clinician's direction of gaze could be if wearing smart glasses.

Our results also show that whilst wearing lead shielded glasses a 6.10 - fold reduction in dose rate to the lens is possible $(p<0.05)$, which is in agreement with previous studies. ${ }^{14,27}$ An important observation is the increased dose rate the clinician's eyes receive despite wearing lead shielded glasses, as the angle of gaze moves to $45^{\circ}$ and $90^{\circ}$ from $0^{\circ}$ with no caudal head tilt. This was also seen in a previous study by Ekpo et $\mathrm{al}^{14}$ who hypothesised that as the angle of gaze moves away from the scattering source, backscatter radiation from the glasses to the lens is received to the clinician. In contrast, a decrease in dose rate was measured for the same movement when the phantom clinician did not wear lead shielded glasses for the furthermost eye from the scattering source. As both eyes were measured in this study, it was confirmed that the eye closest to the scattering source would receive a higher dose rate of radiation in comparison to the eye furthest away from the scattering source, both with and without the presence of lead shielded glasses whilst the phantom clinician was at positions $A$ and $E$. This trend however was not as prominent at positions $B$ and $D$, with dose rate measured to be similar at both eyes. We propose with the use of lead lined smart glasses during interventional procedures, there would be a reduction in the amount of time the clinician would need to look away from the patient. Significantly reducing dose rate received to the lens helping to keep the dose below the threshold for cataracts.

Limitations of this work may include the uncertainties from errors in the TLD readings ${ }^{28}$ the sensitivity of the TLDs used in this study were 0.028 . The experimental room did not fully account for a true interventional radiology environment, as the use of phantoms were employed for this study. Collimation was kept fully open throughout the experiment, which does not truly represent actual clinical practice. The simulated clinician did not change location during this study which should be addressed in future research. The clinician would be required to 
change their position throughout the procedure which is known to have an impact on eye dose.20, 29 The distance between the clinician and scattering source has remained fixed in this study, however it is likely to change within a real clinical environment. It has been shown previously when there is a decrease in proximity from the patient there is a reduction in dose received to the eye lens. ${ }^{30}$ Although all effort was taken to ensure a $15^{\circ}$ caudal angle was achieved, this may not have been perfectly attained for each angle of gaze. The measured scatter cannot be solely attributed to the scattering source (pelvis phantom) as the tube location was not shielded i.e. no leaded table skirt ${ }^{31}$. It is recommended that for future work greater ecological validity be assured with the use of a leaded skirt to remove this limitation. Also, as a head phantom was used to replicate the clinician, further shielding from a lead gown and thyroid shield was not possible, which would absorb scattered radiation $^{32}$. No measures were taken to account for multiple scatter events from within the head phantom. Throughout the experiment the $C$ arm remained static, for the purposes of this pilot study experiment (potential dose protection from the use of lead lined smart glasses) there was no need to move the $C$ arm to different angles. It is noted however that moving the $C$ arm would have an impact on the results. ${ }^{17}, 33$ This study supports further research for glasses use and testing within the clinical setting. Further research is recommended into how changing the $C$ arm angle affects dose rate to the clinician's eye lenses. Additionally, the distance between the patient table and operators eyes ${ }^{20,}{ }^{33}$, the size of the irradiated volume ${ }^{34}$ along with the exposure parameters ${ }^{34}, 35$ can affect the dose to the operator and these have remained constant in this study. Future work could also include the testing of lead line smart glasses within an actual interventional procedure, to establish the impact of clinician's gaze. This would also determine whether wearing smart glasses resulted in increased observation of the patient by the clinician. TLDs are highly sensitive for measuring low level scatter radiation, ${ }^{36}$ a strength of this work. The experiment was conducted on the same day to increase the accuracy of this work, ensuring the same experimental set up was achieved, a further strength of this work.

\section{Conclusion}

A significant reduction in dose rate to the phantom's eye was received when looking directly at the scattering source whilst wearing lead shielded glasses. This experimental study has shown evidence of the potential for dose reduction to the clinician's eye lens. Preliminary experimental findings indicate a new standard of practise may therefore be introduced whilst wearing lead lined augmented reality smart glasses eliminating the need for the clinician to look at fixed position computer monitors during exposures. By introducing lead lined smart glasses into interventional radiology, potential improvements in patient care can be made as the clinician will not always need to look away from the patient to observe a radiographic image. Observation of the patient is particularly important as interventional procedures become more complicated and longer in duration. Smart glasses have 
the potential to make improvements to patient management as they allow the clinician to monitor the patient more dynamically. Further research is needed to assess the efficacy of using smart glasses in interventional procedures, to include clinician acceptability of the technology.

\section{Conflict of Interest}

None. 


\section{References}

1. Google. Glass Start. 2017; https://www.google.com/glass/start/. [Accessed June 2017].

2. Muensterer OJ, Lacher $M$, Zoeller $C$, Bronstein $M$, Kübler J. Google Glass in pediatric surgery: An exploratory study. Int J Surg 2014;12 (4):281-289.

3. Iqbal MH, Aydin A, Lowdon A, Ahmed HI, Muir GH, Khan MS, Dasgupta P, Ahmed K. The effectiveness of Google GLASS as a vital signs monitor in surgery: A simulation study. Int J Surg 2016;36 (Part A):293-297.

4. Nakhla J, Kobets A, De la Garza Ramos R, Haranhalli N, Gelfand Y, Ammar A, Echt M, Scoco A, Kinon M, Yassari R. Use of Google Glass to Enhance Surgical Education of Neurosurgery Residents: "Proof-of-Concept" Study. World Neurosurg 2017;98 (Supplement C):711-714.

5. Krishnamurthy G. Abstract No. 395 - Google Glass in intervention radiology potential applications and limitations. J Vasc Inter Radiol 2015;26 (2, Supplement):S174.

6. Gaur S, Yoon J, Moore W. Abstract No. 383 - Google Glass and interventional radiology: preliminary applications. J Vasc Inter Radiol 2015;26 (2, Supplement):S170.

7. Yoon J, Rajput A, Moore W. Abstract No. 497 - Use of Google Glass in image guided biopsies. J Vasc Inter Radiol 2016;27 (3, Supplement):S220-S221.

8. Chimenti PC, Mitten DJ. Google Glass as an Alternative to Standard Fluoroscopic Visualization for Percutaneous Fixation of Hand Fractures: A Pilot Study. Plast Reconstr Surg 2015;136 (2):328-330.

9. Hendrick RE. Radiation Doses and Cancer Risks from Breast Imaging Studies. Radiol 2010;257 (1):246-253.

10. Brun A, Mor RA, Bourrelly M, Dalivoust G, Gazazian G, Boufercha R, Lehucher-Michel MP, Sari-Minodier I. Radiation protection for surgeons and anesthetists: practices and knowledge before and after training. $J$ Radiol Prot 2018;38 (1):175.

11. Kim JH. Clinical feasibility and usefulness of CT fluoroscopy-guided percutaneous transhepatic biliary drainage in emergency patients with acute obstructive cholangitis. Korean J Radiol 2009;10 (2):144-149.

12. Stoeckelhuber BM, Leibecke T, Schulz E, Melchert UH, Bergmann-Koester CU, Helmberger T, Gellissen J. Radiation Dose to the Radiologist's Hand During Continuous CT Fluoroscopy-Guided Interventions. CardioVasc Intervent Radiol 2005;28 (5):589-594. 
13. Gualdrini G, Mariotti F, Wach S, Bilski P, Denoziere M, Daures J, Bordy JM, Ferrari P, Monteventi F, Fantuzzi E, Vanhavere F. A new cylindrical phantom for eye lens dosimetry development. Radiat Meas 2011;46 (11):1231-1234.

14. Ekpo EU, Bakhshi S, Ryan E, Hogg P, McEntee MF. Operator eye doses during computed tomography fluoroscopic lung biopsy. J Radiol Prot 2016;36 (2):290.

15. Carinou E, Brodecki M, Domienik J, Donadille L, Koukorava C, Krim S, Nikodemová D, Ruiz-Lopez N, Sans-Merce M, Struelens L, Vanhavere F. Recommendations to reduce extremity and eye lens doses in interventional radiology and cardiology. Radiat Meas 2011;46 (11):1324-1329.

16. Domienik J, Rusicka D, Szubert W. A study on the dose distributions near the eye lens and the legs. Part 2 - Interventional radiology. Radiat Meas 2013;5152 (Supplement C):62-66.

17. Liu Y-R, Huang C-Y, Hsu C-H, Hsu F-Y. Dose estimation of eye lens for interventional procedures in diagnosis. Radiat Phys Chem 2017;140 (Supplement C):247-251.

18. Stewart, F.A, Akleyev, et al. ICRP PUBLICATION 118: ICRP Statement on Tissue Reactions and Early and Late Effects of Radiation in Normal Tissues and Organs - Threshold Doses for Tissue Reactions in a Radiation Protection Context. Annals of the ICRP 2012;41 (1-2):1-322.

19. Hiles PA, Mackenzie A, Scally A, Wall B. Recommended Standards for the Routine Performance Testing of Diagnostic X-ray Imaging Systems. York2005.

20. Principi S, Farah J, Ferrari P, Carinou E, Clairand I, Ginjaume M. The influence of operator position, height and body orientation on eye lens dose in interventional radiology and cardiology: Monte Carlo simulations versus realistic clinical measurements. Phys Med 2016;32 (9):1111-1117.

21. Office for National Statistics. 2011 Census: Population estimates by single year of age and sex for local authorities in the United Kingdom. 2011; https://www.ons.gov.uk/peoplepopulationandcommunity/populationandmigratio n/populationestimates/datasets/2011censuspopulationestimatesbysingleyearof ageandsexforlocalauthoritiesintheunitedkingdom. [Accessed February 2019].

22. Kapron AL, Aoki SK, Peters CL, Maas SA, Bey MJ, Zauel R, Anderson AE. Accuracy and feasibility of dual fluoroscopy and model-based tracking to quantify in vivo hip kinematics during clinical exams. J App Biomech 2014;30 (3):461.

23. Rothband. Rothband Catalog. Burnley: Rothband; 2016/17:34.

24. Hogg P, Hogg-Thompson R, Buissink C. OPTIMAX 2016: Optimising image quality for medical imaging. 2017. 
25. Tootell AK, Szczepura KR, Hogg P. Optimising the number of thermoluminescent dosimeters required for the measurement of effective dose for computed tomography attenuation correction data in SPECT/CT myocardial perfusion imaging. Radiog 2013;19 (1):42-47.

26. Pages J, van Loon R. The European Protocol on Dosimetry in Mammography: Applicability and Results in Belgium. Eur Prot Dosim 1998;80 (1-3):191-193.

27. Sans Merce M, Korchi AM, Kobzeva L, Damet J, Erceg G, Marcos Gonzalez A, Lovblad K-O, Mendes Pereira V. The value of protective head cap and glasses in neurointerventional radiology. J NeuorInterv Surg 2015;8 (7):736.

28. Ernst $M$, Manser $P$, Dula $K$, Volken $W$, Stampanoni MFM, Fix MK. TLD measurements and Monte Carlo calculations of head and neck organ and effective doses for cone beam computed tomography using 3D Accuitomo 170. Dentomaxfac Radiol 2017;46 (7):20170047.

29. McLean D, Hadaya D, Tse J. Eye dose to staff involved in interventional and procedural fluoroscopy. J Phys 2016;694 (1):012054.

30. Artur $\mathrm{O}$, Nils K, Charlotta $\mathrm{P}$, Maria M, Tony S, Annette F. Assessment of the occupational eye lens dose for clinical staff in interventional radiology, cardiology and neuroradiology. J Radiol Prot 2017;37 (1):145.

31. Ciraj-Bjelac O, Carinou E, Ferrari P, Gingaume M, Merce MS, O'Connor U. Occupational Exposure of the Eye Lens in Interventional Procedures: How to Assess and Manage Radiation Dose. J Am Coll Radiol 2016;13 (11):13471353.

32. Goren AD, Prins RD, Dauer LT, Quinn B, Al-Najjar A, Faber RD, Patchell G, Branets I, Colosi DC. Effect of leaded glasses and thyroid shielding on cone beam CT radiation dose in an adult female phantom. Dento Max Fac Radiol 2013;42 (6):20120260-20120260.

33. Leyton F, Nogueira MS, Saad J, dos Santos JA, Vano E, Oliveira MA, Ubeda C. Scatter radiation dose at the height of the operator's eye in interventional cardiology. Radiat Meas 2014;71 (Supplement C):349-354.

34. Heidbuchel H, Wittkampf FHM, Vano E, Ernst S, Schilling R, Picano E, Mont L, Group ESCSD. Practical ways to reduce radiation dose for patients and staff during device implantations and electrophysiological procedures. EP Euro 2014;16 (7):946-964.

35. Crowhurst $J$, Whitby $M$. Lowering fluoroscopy pulse rates to reduce radiation dose during cardiac procedures. J Med Radiat Sci 2018;65 (4):247-249.

36. Koivisto $\mathrm{J} \mathrm{H}$, Wolff $\mathrm{J}$ E, Kiljunen $\mathrm{T}$, Schulze $\mathrm{D}$, Kortesniemi M. Characterization of MOSFET dosimeters for low-dose measurements in maxillofacial anthropomorphic phantoms. J App/ Clin Med Phys 2015;16 (4):266-278 